\title{
PROFESSORES, REDATORES E POLÍTICOS: O LUGAR DE JUSTINIANO DE MELLO E SILVA NA IMPRENSA PERIÓDICA OITOCENTISTA ${ }^{1}$
}

\author{
Bárbara da Silva Santos ${ }^{2}$ \\ lattes.cnpq.br/1070262569421016 \\ Cristiano de Jesus Ferronato 3 \\ lattes.cnpq.br/0482207288994322
}

\begin{abstract}
Resumo: As pesquisas que refletem sobre os modelos educacionais abordados nos jornais do século XIX contribuem para a construção da História da Educação, pois elas contêm aspectos educacionais que nos permitem entender o contexto atual nesse campo. Nesse ínterim, o presente artigo busca refletir acerca dos agentes participantes dos jornais, destacando Justiniano de Mello e Silva, bem como apresentar a contribuição da imprensa periódica nesse período para as pesquisas em História da Educação. Homens de letras, os redatores da imprensa do século XIX, ao disporem de certo domínio com as palavras, redigiram textos que ultrapassaram a temática da política. Esta pesquisa está inserida no campo referido e, para alcançarmos o objetivo, empregamos o método de levantamento e análise de fontes documentais e bibliográficas, as quais consistiram no jornal "Sete de Março" e em trabalhos que pesquisam sobre redatores, imprensa e educação. Esta metodologia consiste na organização dos documentos a fim de elaborar um mapeamento dos conteúdos.
\end{abstract}

Palavras-chave: Educação; Imprensa; Jornal Sete de Março; Redatores; Sociabilidade.

\section{TEACHERS, WRITERS AND POLITICIANS: THE PLACE OF JUSTINIANO DE MELLO E SILVA IN THE PERIODICAL PRESS OF THE NINETEENTH CENTURY}

\begin{abstract}
The studies that reflect on the educational models covered in the newspapers of the nineteenth century contribue to the construction of the History of Educa-

${ }^{1}$ Uma primeira versão deste artigo foi apresentada no VI Encontro Norte e Nordeste de História da Educação, realizado na Universidade Federal do Rio Grande do Norte em outubro de 2016.

${ }^{2}$ Mestranda em Educação pela Universidade Tiradentes, Brasil. Contato:

ss.barbarasilva@gmail.com.

3 Doutor em Educação. Docente da Universidade Tiradentes, Brasil. Contato:

cristiano jesus@unit.br.
\end{abstract}


tion, for in them context of this field. However, this article aims to reflect on those participating in the newspapers that highlight Justiniano de Mello e Silva, as well as presenting the contribution of the periodical press of this period for research in, Education History. Men of letters, the writers of the press of the nineteenth century, had dominion with the words, they wrote texts that exceeded the subject of politics. This research is inserted in this field, and to achieve the goal, we use the survey method and analysis of documentary and bibliographic sources, which consisted of the newspaper "Seven March" and work researching writers, media and education. This methodology consists in the organization of the documents, in order to prepare a mapping of content.

Keywords: Education; Press; Journal Sete de Março; Writers; Sociability.

\section{Introdução}

Homens de letras, os redatores da imprensa do século XIX, ao disporem de certo domínio com as palavras, redigiram textos que ultrapassaram a temática da política. Diante desse aspecto, questões sobre a Educação foram veiculadas, não somente em periódicos especializados, em muitos casos, por responsáveis pela redação de jornais no século XIX, pois, como homens públicos, exerciam mais de uma atividade.

Justiniano de Mello e Silva, personagem inserido nesse contexto, nasceu em 08 de janeiro de 1853, na cidade de Divina Pastora, província de Sergipe. Colaborou em periódicos como 25 de Março (1876), O Paranaense (1877), Gazeta Paranaense (1882), Jornal do Commercio (1882), Revista Azul (1893) e Cenaculo (1895). Além disso foi poeta, historiador, político e professor de instituições escolares nas províncias do Paraná e de Sergipe. No jornal Sete de Março, editado em Curitiba, órgão oficial do Partido Conservador, ele atuou até 1891 como redator desde a primeira edição, que foi publicada em 24 de abril de 1888. Nas páginas deste periódico, Justiniano fez delas um espaço ideal de propagação das suas ideias pedagógicas e educacionais.

Como nossa fonte está inserida na segunda metade do século XIX, época em que os jornais assumiram um papel fundamental para a disseminação de ideias, empregamos o método de levantamento e análise de 
fontes documentais e bibliográficas. Essa metodologia consiste na organização dos documentos a fim de elaborar um mapeamento dos conteúdos.

\section{Devemos levar em consideração que}

O documento não é inócuo. É antes de mais nada o resultado de uma montagem, consciente ou inconsciente, da história, da época, da sociedade que o produziram, mas também das épocas sucessivas durante as quais continuou a viver, talvez esquecido, durante as quais continuou a ser manipulado, ainda que pelo silêncio. $\mathrm{O}$ documento é uma coisa que fica, que dura, e o testemunho, o ensinamento (para evocar a etimologia) que ele traz devem ser em primeiro lugar analisados desmistificando-lhe o seu significado aparente. O documento é monumento. Resulta do esforço das sociedades históricas para impor ao futuro - voluntária ou involuntariamente - determinada imagem de si próprias. (LE GOFF, 1990, p. 548-549).

Por essa razão, o documento necessita ser analisado em um conjunto de circunstâncias que enquadra tanto aqueles que o produziram quanto os acontecimentos que o envolveram. Partimos, então, do princípio de que, ao utilizar o jornal como fonte de pesquisa e, também,

[...] como fonte documental para a história e a história da educação deve considerar alguns fatores: o contexto em que foi produzido, sem secundarizar a fonte de pesquisa; a identificação de quem o apresenta, significando de qual segmento social o jornal é porta voz; seus objetivos; o público que quer atingir; qual o seu teor; o momento de sua publicação e duração. (ANDREOTTI, 2004, p. 18).

É nesse seguimento que o artigo em questão busca refletir acerca dos agentes participantes dos jornais do século XIX, onde destacamos Justiniano de Mello e Silva, visando apresentar a contribuição da imprensa desse período para as pesquisas em História da Educação. Utilizamos este tipo de documento como fonte para nosso estudo por ele ter desempenhado, no século XIX, um "papel crucial [...] na educação diária das pessoas", bem como "na função exercida por eles na própria evolução da sociedade." (CAMPOS, 2012, p. 49). 


\section{Escritos panfletários: os redatores da imprensa na segunda metade dos oitocentos}

O jornal é a verdadeira forma da república do pensamento. É a locomotiva intelectual em viagem para mundos desconhecidos, é a literatura comum, universal, altamente democrática, reproduzida todos os dias, levando em si a frescura das ideias e o fogo das convicções. (Machado de Assis)

Diante das palavras de Machado de Assis (2008, não p.), faz-se necessário conhecer quem foram os sujeitos que estavam envolvidos tanto na produção quanto na veiculação da imprensa periódica da segunda metade dos oitocentos. Conforme Morel (2005), as ideias que circulavam nos jornais impressos do século XIX mantinham uma estreita relação com a palavra falada. Isto porque,

[...] o surgimento da imprensa periódica no Brasil não se deu numa espécie de vazio cultural, mas em meio a uma densa trama de relações e formas de transmissão já existentes, na qual a imprensa se inseria. Ou seja, o periodismo pretendia, também, marcar e ordenar uma cena pública que passava por transformações nas relações de poder que diziam respeito a amplos setores da hierarquia da sociedade, em suas dimensões políticas e sociais. A circulação de palavras - faladas, manuscritas ou impressas - não se fechava em fronteiras sociais e perpassava amplos setores da sociedade que se tornaria brasileira, não ficava estanque a um círculo de letrados, embora estes, também tocados por contradições e diferenças, detivessem o poder de produção e leitura direta da imprensa. (MOREL, 2005, p. 19)

Nesse contexto, aqueles que pertenciam ao grupo responsável pela publicação dos periódicos contribuíram, de maneira direta ou indiretamente, no propósito de configurar um cenário público social. Os tipógrafos, os impressores, os redatores, os colaboradores, os assinantes, os correspondentes e os leitores caracterizavam-se por agentes da imprensa, sendo o redator o que trazia singularidade aos jornais, pois ele

[...] agrupava funções que iam desde a organização formal do jornal até a definição do conteúdo por ele propalado. Ao escre- 
ver a maior parte dos artigos e determinar o formato do periódico, acabava personificando-o e funcionando como seu porta-voz principal, de modo que o debate travado na imprensa da época configurava-se menos institucional, isto é, entre diferentes jornais, do que numa discussão estabelecida entre redatores. (OLIVEIRA, 2010, p. 6).

Ou seja, a atividade do sujeito responsável por "moldar" os jornais era tanto a de escolher qual temática seria divulgada quanto a de contribuir para o conteúdo veiculado. Desse modo, mesmo sendo o redator a figura que caracterizava o periódico, seu eventual desligamento não "[...] significava [...] a possibilidade de alteração do perfil de uma folha”, em virtude de existirem outros membros contribuintes: os colaboradores. Esses, apesar de comumente terem participação anônima, eram fundamentais para a constituição das publicações, “[...] já que a maior parte dos redatores desempenhava outras funções fora da tipografia, e necessitava de auxiliares, mesmo que temporários, que dessem sustentação ao periódico". (OLIVEIRA, 2010, p. 8).

Os colaboradores participavam de maneira impessoal, no sentido de que eles não se envolviam com os debates mais promissores da época; ou seja, eles não direcionavam as temáticas dos seus textos para algo ou alguém específico. Essa tarefa ficava por conta dos redatores que, quando se tratava de política, fortificavam as suas palavras para protestar no que diz respeito ao que estava posto em questão.

A fim de delinearmos um perfil dos redatores do período, cabe indagarmos quem eram esses homens e quais os seus propósitos, pois eles buscavam conquistar "adeptos para uma causa, seja ela empresarial ou política, e os artifícios utilizados para esse fim são múltiplos.” (CAPELATO, 1994, p. 15).

De esfera pública, os redatores brasileiros perpassavam pela cultura impressa de outros países, trazendo ideias de fora para serem seguidas pela imprensa do Brasil. Eram homens de letras que, em sua maioria, integravam grupos políticos e traziam em seus jornais não somente reflexões sobre temas comuns que estavam sendo discutidos, mas também, e principalmente, ofensivas políticas contra os partidos opositores. De acordo com Oliveira (2010, p. 7), 
A utilização da imprensa como meio de criação, propagação e combate de ideias conferia ao redator um caráter eminentemente público, ainda que os artigos impressos nos periódicos fossem majoritariamente anônimos. Conhecidos também como "publicistas", os redatores faziam da sua condição uma via de projeção social associada às carreiras políticas.

Esse modo de propagar e de combater ideias atribuía aos redatores um estilo tido como "panfletário". Segundo Morel (2005, p. 36-37),

\begin{abstract}
A maioria dos homens de letras dessa geração, independente do posicionamento político, escrevia no chamado estilo panfletário, que expressou uma das fases mais criativas e vigorosas dos debates políticos mundiais e da imprensa brasileira em particular, só vindo a desaparecer na segunda metade do século XX. O estilo panfletário [...] alcançava eficácia por várias características retóricas interligadas, como: capacidade de convencer e de atacar, espírito mordaz e crítico, linguagem literária, sátira, requerendo ao mesmo tempo densidade doutrinária e ideológica e agilidade para expressar, em situações específicas e circunstanciais, uma visão de mundo geral e definida.
\end{abstract}

O "estilo panfletário" dos redatores de jornais se processou em conformidade com os acontecimentos do período. Com as constantes mudanças ocorridas no século XIX, a imprensa tornou-se um dos principais meios para a veiculação dos debates. Por essa ocasião, aqueles que escreviam em jornais tinham como intuito propagar o seu posicionamento de várias formas, ora proferindo palavras ofensivas, ora utilizando termos literários, com o propósito de comparar os seus opositores com personagens oriundos da literatura. Alcançar o máximo de circulação era a intenção do jornal panfletário. Tal estilo atribuído aos periódicos não se justificava com o fato desses escritos terem o formato de panfleto, mas por carregarem em si a ideia de produtividade e agilidade no fluxo da sua veiculação.

Esse cenário de transformações fazia parte do cotidiano da sociedade, o qual se configurou como formador de ideias e posicionamentos com a perspectiva de lançar ao público as questões emergentes no âmbito da política, da economia, da educação, entre outras. Além disso, aqueles que respondiam pelos jornais integravam um ambiente de afinidades po- 
líticas, sociais e culturais, o qual se apresentava com certa complexidade conforme levava esses sujeitos a exporem, de alguma maneira, suas convicções.

Temos como exemplo desse tipo de relação o discurso de saudação do jornal Dezenove de Dezembro a Justiniano de Mello, quando assumiu o cargo de secretário do governo do Paraná, publicando-se a mensagem:

Vos saudamos como um dos homens que tem dedicado seus melhores dias aos interesses do povo e a instrucção da mocidade [...] Vós sois um dos homens que tem contribuído muito para o progresso e civilização, palavras que pela sua universalidade, pela sua indeterminação, pela vontade que confusamente envolvem; agradam, lisongeam, enthusiasmam, electrisam. (DEZENOVE DE DEZEMBRO, 07/03/1877, p. 3)

A veiculação desse discurso demonstrou o quanto o sujeito mencionado estava inserido nos diversos campos que eram comuns aos redatores da época: o político e o acadêmico. Diante dessas condições e com o intuito de melhor propagar as ideias do partido que pertencia, o sergipano defendeu um projeto que prescrevia a criação de um periódico para as suas publicações, proferindo o seguinte discurso:

[...] a politica precisa de uma propaganda activa, que não só attraia ao grêmio dos partidos novos sectários, como que mantenha accêsa a chamma das dedicações, e concite as energias adormecidas. [...] todas as agregações partidárias, quando colocadas nas posições officiaes, esquecerem rapidamente os deveres que as ligas á opinião publica, sempre indagadora e exigente. [...] a imprensa tem a incomparavel virtude de aproximar os espíritos, de estabelecer a harmonia e a mais salutar uniformidade entre os propugnadores da mesma doutrina. [...] as administrações conservadoras tem o direito de exigir de seus coreligionarios a defesa dos actos que as recommendem. [...] agora mais que nunca tornva-se urgente a creação de orgão conservador; pois a folha que publica o expediente do governo havia cortado com o jornal liberal toda a discussão. [...] a proposta do Sr Dr. Tertuliano, apoiada por todos os correligionários presentes, tinha a mais alta significação no presente, pois inaugurava uma nova phase de salutar agitação para o grande partido em cujas fileira milita. (DEZENOVE DE DEZEMBRO, 29/09/1877, p. 4). 
A partir do seu posicionamento, Justiniano de Mello foi escolhido para ser o redator do jornal responsável por defender os princípios conservadores, o Sete de Março. Ao exercer esse cargo, ele conseguiu, de maneira mais significativa, propagar as suas considerações acerca do contexto do período e suas defesas direcionadas aqueles argumentos contrários ao perfil do periódico. Isso porque, quando as ideias dos redatores eram lançadas para o social, adquiriam a função de "mediadores que interpretem os preceitos" para a formação de opiniões sobre os diversos temas por eles redigidos. Consequentemente, esses indivíduos atuaram estabelecendo condições que possibilitaram os sujeitos sociais seguirem "a sua vocação humana”. (BAUMAN, 2010, p. 100-101).

\section{Os jornais no século XIX e a pesquisa em História da Educação}

No século XIX, a imprensa periódica teve uma participação significativa para a circulação de ideias e debates políticos e educacionais que permeavam o cotidiano brasileiro. Hoje, tal fonte é comumente utilizada pelas pesquisas no âmbito da História da Educação, pois ela contribui para o resgate de aspectos da história da época, tornando-se fundamental "[...] na reconstrução de um tempo passado, tanto em relação aos fatos relatados, quanto à concepção transmitida a partir desses fatos." (ANDREOTTI, 2004, p. 17). Logo, conforme Chartier,

História e memória estão fortemente interligados. O conhecimento histórico pode ajudar a dissipar as ilusões ou interpretações errôneas que há muito desorientaram as memórias coletivas. E, inversamente, as cerimônias de lembranças e institucionalização dos lugares da memória são com frequência a inspiração para indagações históricas originais. Todavia, memória e história não são idênticas. A memória é guiada por exigências existenciais de comunidades para as quais a presença do passado no presente é um elemento essencial para a construção do seu ser coletivo. (CHARTIER, 2014, p. 65). 
Na História da Educação, os dois elementos acima referidos por Chartier são fundamentais para as questões de pesquisa deste campo, levando em consideração que:

"[...] as obras devem ser entendidas como produções coletivas e
como o resultado de "negações”, que consistem não somente na
aquisição de objetos para o palco, apropriação de linguagem ou
reutilização simbólica de práticas sociais e rituais mas também,
e fundamentalmente, em "transações" que são sempre instáveis
e sempre renovadas, entre a obra em sua identidade perpetuada
e as várias formas de sua transmissão e suas representações."
(CHARTIER, 2014, p. 308-309).

Visto como uma "produção coletiva”, os impressos jornalísticos, nesse período, traziam em suas páginas, principalmente, o posicionamento político daqueles que os redigiam. Vale ressaltar que a maioria dos periódicos pertencia a partidos políticos e os seus colaboradores escreviam textos ora literários, ora de cunho educacional, e, por vezes, exteriorizavam o seu pensamento a despeito de acontecimentos notáveis do período. Isso porque "[...] o jornal no Brasil do século XIX foi tomado como um veículo de educação, civilização e instrução do povo." (SILVA, NASCIMENTO \& ZICA, 2010, p. 223). Dessa forma,

[...] os impressos representam significativos mananciais de informações sobre o repertório de uma época e sobre os usos que dele faziam seus colaboradores. Neles se fazem presentes projetos, opiniões, conflitos e debates, que apontam a complexidade dos interesses e experiências dos indivíduos e dos contextos em que se inscrevem. (SILVA, NASCIMENTO \& ZICA, 2010, p. 223).

Nessa perspectiva, acreditamos que este tipo de documento é essencial para a busca do que ocorreu naquela época. Tomamos, como exemplo, os saberes produzidos naquele tempo, por quem eles foram pensados e, a partir disso, os embates travados pelas "elites culturais".

As "elites culturais" se constituíram entre o cultural e o político, pois “[...] não existem como entidades autónomas [...]. Estão, pelo contrário, ligadas à sociedade que as rodeia e são precisamente esses laços, especialmente políticos, que lhes conferem uma identidade." (SIRINEL- 
LI, 1998, p. 264). Logo os jornais surgem como veículo para a circulação da cultura, o que o autor caracteriza como "poder de influência" das elites para a sociedade.

As reflexões de Michel de Certeau (1998) sobre o que são "estratégias" e "táticas" caminham na mesma direção quando buscamos distinguir os sujeitos dominantes dos "dominados". De acordo com o autor, "estratégia" é "[...] o cálculo (ou a manipulação) das relações de forças que se torna possível a partir do momento em que um sujeito de querer e poder [...] pode ser isolado.” e que “[...] postula um lugar suscetível de ser circunscrito como algo próprio e ser a base de onde se podem gerir as relações com uma exterioridade de alvos ou ameaças (os clientes ou os concorrentes, os inimigos [...])." (CERTEAU, 1998, p. 99). "Tática” ele define como "[...] a ação calculada que é determinada pela ausência de um próprio. [...] A tática não tem por lugar senão o do outro. E por isso deve jogar com o terreno que lhe é imposto tal como organiza a lei de uma força estranha." (CERTEAU, 1998, p. 100).

Sob a pesquisa do historiador mencionado e relacionando ao jornal Sete de Março, as “estratégias” correspondem aos seus escritores e o periódico em si, pois eles são detentores de certo tipo de "poder" e instituem convicções sobre os seus leitores. Esses, por sua vez, são pertencentes às "táticas" devido a sua "ausência de poder". Há, então, uma relação de "consumo" que geram diferentes "maneiras de fazer" com o produto, as quais os fabricantes não esperam, sejam elas positivas ou não. "Tratase de combates ou de jogos entre o forte e o fraco, e das 'ações' que o fraco pode empreender.” (CERTEAU, 1998, p. 97). Se o “[...] escrevente público continua a ser uma figura clássica da sociabilidade urbana, os progressos da escolarização e da alfabetização tornam então amplamente possível a delegação da escrita no interior do mesmo ambiente social." (CHARTIER, 2002, p. 92).

A imprensa periódica teve um papel fundamental na difusão de ideias, nessa perspectiva, o jornal Sete de Março foi fundado com o intuito de divulgar as defesas do Partido Conservador, do qual Justiniano fazia parte. Em razão do momento em que estava inserido, seus colaboradores eram membros e apoiadores do partido, por isso grande parte dos 
textos propunha temas para o debate político. Mas não só de escritos políticos ele era composto, uma vez que também publicava seções com poemas, notícias, contos literários, anúncios diversos, bem como artigos sobre Educação.

Em nossa pesquisa com o jornal, percebemos que grande parte das edições apresentava discussões sobre educação, constatando, assim, que mesmo o periódico não sendo deste campo - o educacional -, também circulavam ideias pedagógicas. Quanto a isso, Faria Filho (2009, p. 134) destaca que, "o jornal foi visto como uma importante estratégia de construção de consensos, de propaganda política e religiosa, de produção de novas sensibilidades, maneiras e costumes. Sobretudo os jornais foram vistos como importante estratégia educativa”.

Justiniano de Mello foi o que mais contribuiu ao escrever diversos textos relacionados à Pedagogia, à Educação e à Instrução, além de outros manuscritos com temáticas voltadas para as áreas do Direito e da Religião. Ele argumentou sobre os processos educacionais vigentes e foi além daquilo que estava sendo discutido na província do Paraná. Levando em consideração que o período estudado sofreu significativas transformações em vários campos, principalmente no educacional, percebemos que este professor discutiu as circunstâncias do momento, demonstrando o seu pensamento nos textos veiculados no jornal Sete de Março.

Nesse caso, devemos notabilizar, então, a relação existente entre imprensa e a História da Educação atentando-se ao fato de que os sujeitos que compunham os espaços políticos e jornalísticos também se faziam presentes no universo de debates sobre a educação em todo o Brasil, tornando-se agentes ativos que participavam, em sua maioria, dos três ambientes. Assim,

A História da Educação, ao resgatar esses momentos entendendo-os como intrinsecamente educativos, contribui para que o processo de construção e consolidação da nação brasileira possa ser hoje entendido em plenitude e forneça elementos para que a atualidade das relações sociais existentes no Brasil, e no interior dela a educação, com seus desafios e perspectivas venha a ser desvelada e assim apontar soluções para os impasses que enfrenta a sociedade brasileira em nome da realização de um estado de igualdade de fato. Pensar a educação e imprensa do século 
XIX é, portanto, um dos momentos desse recontar a história brasileira sob novos parâmetros interpretativos e com fontes praticamente inéditas para o campo educacional. (MIZUTA, FARIA FILHO \& PERIOTO, 2010, p. 11).

Dito de outro modo, as pesquisas que refletem sobre os modelos educacionais abordados nos jornais do século XIX contribuem para a construção da História da Educação, pois neles contêm aspectos educacionais que nos permitem entender o contexto atual desse campo.

\section{Considerações finais}

As pesquisas que utilizam os textos produzidos e veiculados nos jornais do século XIX trazem as principais propostas educacionais discutidas na época, visto que a imprensa periódica foi palco de debates e críticas entre os sujeitos que mantinham cargos na imprensa e assumiam um caráter de homens públicos; isto é, os redatores de jornais desempenharam papéis ora de político, ora de professor, por vezes, até ambos.

A defesa dos interesses políticos dos redatores e a escrita de textos que envolvem temas da educação apontam que, mesmo preocupados em contribuir para a formação de opiniões, participavam, querendo ou não, da configuração de uma sociedade que se buscava consolidar como nação organizada.

O que se tem notado, à medida que estabelecemos nossas reflexões sobre os textos escritos por Justiniano de Mello, é o seu esclarecimento e a sua aproximação com as discussões pertinentes daquele período. A tendência de publicar essas ideias em periódicos nos leva a refletir sobre suas intenções, pois ele fez dos jornais um mecanismo que possibilitou a circulação dessas temáticas. Como figura pertencente da "administração escolar”, o personagem pretendeu que circulasse para além da elite letrada, ou seja, para aqueles que de alguma forma participavam do aparelho que organizava a instrução da província.

Diante disso, percebemos que a análise dos discursos veiculados por jornais do século XIX nos faz compreender o cotidiano daquela soci- 
edade. Não vemos o que era noticiado como uma "verdade absoluta" do que estava acontecendo, mas um jogo de verdades e mentiras envolvendo relações de poder. Mesmo assim, não devemos deixar de lado a relevância desse tipo de estudo para o cenário atual da educação, considerando que os atores que compunham a imprensa da época também permeavam os campos da política e da educação.

\section{Referências}

ANDREOTTI, Azilde Lina. A formação de uma geração: a educação para a promoção social e o progresso do país no jornal $A$ voz da infância da Biblioteca Infantil Municipal de São Paulo (1936-1950). 2004. Tese (doutorado em Educação) - Faculdade de educação, Universidade de Campinas, São Paulo.

ASSIS, Machado de. O jornal e o livro. In: Coleção digital Machado de Assis. Brasília: Ministério da Educação, UFSC (NUPILL), Portal Domínio Público, 2008.

BAUMAN, Zygmunt. A educação das pessoas. In: Legisladores e intérpretes: sobre modernidade, pós-modernidade e intelectuais. Tradução: Renato Aguiar. Rio de Janeiro: Zahar, 2010. p. 100-116.

CAMPOS, Raquel Discini de. No rastro de velhos jornais: considerações sobre a utilização da imprensa não pedagógica como fonte para a escrita da história da educação. Revista Brasileira de História da Educação, v. 12, n. 1 (28), p. 45-70, 2012.

CAPELATO, Maria Helena Rolim. A imprensa na história do Brasil. 2. Ed. São Paulo: Contexto/EDUSP, 1994.

CERTEAU, Michel de. A invenção do cotidiano: 1, Artes de fazer. Petrópolis: Vozes, 1998.

CHARTIER, Roger. Os desafios da escrita. Tradução: Fulvia M. L. Morreto. São Paulo: UNESP, 2002.

CHARTIER, Roger. A mão do autor e a mente do editor. Tradução: Schlesinger, George. São Paulo: UNESP, 2014.

FARIA FILHO, Luciano Mendes de; CHAMON, Carla Simone; INÁCIO, Marcilaine Soares. Apresentação. In: Políticos, literatos, intelectuais: o debate público sobre educação em Minas Gerais. Belo Horizonte: Mazza Edições, 2009. 
LE GOFF, Jacques. História e memória. Tradução: Bernardo Leitão. Campinas: Editora da UNICAMP, 1990. (Coleção Repertórios).

MIZUTA, Celina Midouri Murasse; FARIA FILHO, Luciano Mendes de; PERIOTO, Marcília Rosa. Apresentação. In: Império em debate: imprensa e educação no Brasil Oitocentista. Maringá: Eduem, 2010. p. 9-13.

MOREL, Marco. As transformações dos espaços públicos: imprensa, atores políticos e sociabilidades na Cidade Imperial, 1820-1840. São Paulo: Hucitec, 2005.

OLIVEIRA, Carlos Eduardo França de. Tipógrafos, redatores e leitores: aspectos da imprensa periódica no Primeiro Reinado. Revista Brasileira de História \& Ciências Sociais, v. 2, n. 3, 2010, p. 1-12.

SANTOS, Anderson. "Raciocinar com rectidão": as lições do compêndio Lições de Philosophia Elementar Racional e Moral de José Soriano Souza (1871). 2016. 133 f. Dissertação (Mestrado em Educação) - Universidade Tiradentes, Aracaju, 2016.

SILVA, Carolina Mostaro Neves da; NASCIMENTO, Cecília Vieira do; ZICA, Matheus da Cruz e. Imprensa e Educação na segunda metade dos oitocentos. In: MIZUTA, Celina Midouri Murasse; FARIA FILHO, Luciano Mendes de; PERIOTO, Marcília Rosa. Império em debate: imprensa e educação no Brasil Oitocentista. Maringá: Eduem, 2010. p. 223-251.

SIRINELLI, J. F. As elites culturais. In: RIOUX, J. P.; SIRINELLI, J. F. (Orgs.). Para uma história cultural. Lisboa: Estampas, 1998.

SIRINELLI, J. F. Os intelectuais. In: RÉMOND, R. (Org.). Por uma história política. Rio de Janeiro: FGV, 2003. p. 231-270.

VIDAL, Diana Gonçalves. O campo da História da Educação no Brasil. In: VASCONCELOS, José Geraldo; NASCIMENTO, Jorge Carvalho do (Org.). História da Educação no Nordeste Brasileiro. Fortaleza: Edições, UFC, 2006.

\section{Periódicos}

DEZENOVE DE DEZEMBRO. 17/07/1879; 07/03/1877; 29/09/1877; 28/o8/1879. Disponível em: <http://memoria.bn.br>. Acesso em: 11 out. 2015 .

JORNAL DE SERGIPE. 06/03/1879. Disponível em: <http://memoria.bn.br>. Acesso em: 12 out. 2015.

O PARANAENSE. 16/02/1879; 21/12/1879; 25/01/1880. Disponível em: <http://memoria.bn.br> . Acesso em: 10 out. 2015.

SETE DE MARÇO. 24/04/1888; 06/06/1888; 13/06/1888; 20/06/1888; 
28/12/1889; 19/01/1890; 15/02/1890; 22/02/1890; 1 10/o3/1890; 15/o3/1890; 22/03/1890; 14/06/1890; 21/o6/1890; 31/o8/1890; 04/11/1890; 18/11/1890; 06/12/1890; 17/01/1891. Disponível em: <http://memoria.bn.br>. Acesso em: 20 mai. 2015.

Recebido em 10 de outubro de 2016. Aprovado em 10 de dezembro de 2016. 